\title{
The Nobel Laureate W.C. Roentgen and His X-Rays
}

\author{
Rajinder Singh*
}

(Received 15 May 2016)

\begin{abstract}
The first time, in 1901, the Physics Nobel Prize was awarded to Wilhelm Conrad Roentgen, the discoverer of the X-rays. At that time neither the nominees nor the nominators were well-informed about the processes. Equally, it was a challenge for the Nobel Committee and the Royal Swedish Academy of Sciences, Stockholm, to find out "the physicist", out of many nominated persons, who deserves the award. The nomination letters, the report of the Nobel Committee and other documents dealing with W.C. Roentgen, were obtained from the Academy. The analysis of their results is given in the present communication.
\end{abstract} X-rays.

Key words: Cathode rays, Philipp Lenard, Physics Nobel Prize, Wilhelm Conrad Roentgen,

\section{INTRODUCTION}

The Swede Alfred Nobel, a successful inventor and businessman, died on December 10, 1896. In accordance to his testament five prizes in the fields of Chemistry, Physics, Medicine and Physiology, Literature and Peace were established. ${ }^{1}$ According to A. Nobel's Will:

The whole of my remaining realizable estate shall be dealt with in the following way: the capital, invested in safe securities by my executors, shall constitute a fund, the interest on which shall be annually distributed in the form of prizes to those who, during the preceding year, shall have conferred the greatest benefit to mankind. The said interest shall be divided into five equal parts, which shall be apportioned as follows: one part to the person who shall have made the most important discovery or invention within the field of physics; ... The prizes for physics and chemistry shall be awarded by the Swedish Academy of Sciences; ... (emphasis added).

(http://www.nobelprize.org...)
It took almost five years till the Nobel Foundation was established. After that, it immediately started with the work. The task was not easy, as no one knew - How the scientific community is going to react? How to inform the nominators about the process of nomination? What are the powers of the Nobel Committee and its members? In this context the case study of the first Physics Nobel Laureate, Wilhelm Conrad Roentgen, the discoverer of the X-rays, is of interest.

Much has been written on W.C. Roentgen's life and work. So far as the award of the Nobel Prize is concerned, according to the best of my knowledge, the published literature does not give the detail about: (a) The opinion of the nominators on his work. (b) Views of the Nobel Committee and the Royal Swedish Academy of Sciences, Stockholm, about the discovery, and (c) W.C.

1 For Indian nominators and nominees in all the five fields, see, Singh R., India's Nobel Prize nominators and nominees - The praxis of nomination and geographical distribution, Shaker Verlag, Aachen, 2016. Singh R., Die Nobelpreise und die indische Elite, Shaker Verlag, Aachen, 2016.

* Research Group - Physics Education and History of Science, Department of Physics, University of Oldenburg, 26111 Oldenburg, Germany. E-Mail: rajinder.singh@uni-oldenburg.de 
Roentgen's as nominator. The present article intends to fulfil this gap.

\section{Setting the Stage for the Physics Nobel Prize}

After the publication of Alfred Nobel's Will in the Swedish newspaper, the Norwegian Parliament, which is responsible for the Nobel Peace Prize, started receiving letters from various persons, who wanted to receive the award. For instance, D.D. Richardson, U.S.A., in a letter of Jan. 7, 1897, asked to consider himself for the Prize. Before issuing the official guidelines, in January 1901, the Norwegian Nobel Committee received 130 letters (Nielsen and Nielsen, 2001, pp. 58-86). In the case of the Physics Nobel Prize for the year 1901, two Americans H.A. Rowland and R.H. Thurston nominated themselves (Crawford et al. 1987, pp. 20-21). They were disqualified as according to $\S 7$ of the "Code of Statutes" “... a direct application for a Prize will not be taken into consideration" (Crawford et al. 1987, pp. 224).

Some of the nominators found it difficult to interpret the term discovery/invention "during the preceding year, shall have conferred the greatest benefit to mankind." For instance, Max von Pettenkofer, Munich, who proposed Roentgen, wrote that according to the Foundation's documents the nomination should be made for the most important discovery or invention in the preceding year, that is, in 1899. Thus I am not in the position to nominate a candidate. Perhaps the status could be interpreted in a different way. The proposal can be made for the discovery, whose importance became clear after some time. In this case I shall like to suggest W.C. Roentgen. ${ }^{2}$ E.
Warburg, Berlin, tried to justify that though the discovery was made by Roentgen in 1895, the documents show that the work on this topic was continued and published in the "Wiedemanns Annalen" 64, 1898. ${ }^{3}$ F. von Recklinghausen tried to argue that as the Prize is being awarded for the first time, perhaps it should be possible to consider the discoveries from the last five years. ${ }^{4}$ In 1901, the first Nobel Laureate Roentgen wrote that a candidate can only be nominated for the recent contributions. From the year he found a number of good works, but none of them as worth of the Nobel Prize. ${ }^{5}$

\section{Nominating W.C. Roentgen and P. Lenard for the Physics Nobel Prize}

According to the document of the Nobel Foundation - "Proposals for Professor Roentgen" the following twelve Germans nominated Roentgen for the undivided award: F. von Hefner-Alteneck, W. von Bezold, R.A. von Koelliker, A. Fick, M. von Pettenkofer, F. Reuleaux, G.A. Zeuner, M. Planck, A. Dohrn, E. Warburg, O. Struve and F. von Recklinghausen (see Table 1) (Küppers et al. 1982, p. 19; Crawford, 2002, pp. 20-21).

According to the rule and regulations of the Foundation, it is expected that the proposal is grounded with documentations such as the list of publications or details of the discovery. The first eight did not see need to ground their proposals. F. von Hefner-Alteneck sent a list of Roentgen's important publications. The last three tried to discuss the issue of the discovery/invention "in the preceding year" (see under section "Setting the Stage ...").

\footnotetext{
2 von Pettenkofer M. to N.C., Jan. 19, 1901 (original in German).

3 Warburg E. to N.C., Jan. 18, 1901 (original in German).

${ }^{4}$ von Recklinghausen F. to N.C., Jan 27, 1901 (original in German).

${ }^{5}$ W.C. Roentgen to N.C., Jan. 27, 1901 (original in German).
} 
Table 1: W.C. Roentgen's nominators.

\begin{tabular}{|l|l|}
\hline S. No. & Nominator \\
\hline 1. & W. von Bezold \\
\hline 2. & A. Fick \\
\hline 3. & R.A. von Koelliker \\
\hline 4. & M. von Pettenkofer \\
\hline 5. & G.A. Zeuner ${ }^{9}$ \\
\hline 6. & M. Planck ${ }^{11}$ \\
\hline 7. & O. Struve ${ }^{12}$ \\
\hline 8. & A. Dohrn ${ }^{13}$ \\
\hline 9. & F. von Hefner-Alteneck \\
\hline 14 \\
\hline 11. & F. Reuleaux ${ }^{15}$ \\
\hline 12. & E. Warburg ${ }^{16}$ \\
\hline
\end{tabular}

From Sweden, B. Hasselberg, S. Arrhenius, H.H. Hildebrandsson, Robert Thalén and Knut Angström, in a joint letter, proposed W.C. Roentgen and P. Lenard for a shared award. ${ }^{18}$ They were also the members of the Nobel Committee. As the nominators and the members of the Nobel Committee were the same persons, not surprisingly the report of the Nobel Committee has very similar wording as the nomination letter (Detail under the report of the Nobel Committee, 1901).

S.P. Thompson, U.K., was the only person to propose P. Lenard for the unshared award (Crawford, 2002, pp. 20-21; Küppers et al. 1982, p. 19).

\section{Report of the Nobel Committee}

According to the detail summary of the translated report (original is Swedish) - We the undersigned Member of the Nobel Committee (B. Hasselberg, Knut Angström, H.H. Hildebrandsson, Rob. Thalén, Svante Arrhenius) propose the Royal Swedish Academy of Sciences that the Prize be equally shared between Prof. Wilhelm Conrad Roentgen, Munich; and Prof. Philipp Lenard, Kiel (Report on Nobel Committee, 1901).

In the case of Roentgen, the members argued - The scientific discovery, for which Prof. Roentgen is nominated so well-known that it is needless to give detailed explanation. In the end of 1895, at the "Wuerzburger Phys. Med. Gesellschaft" (Physical Medical Society, Wuerzburg) he reported "Ueber eine neue Art von Strahlen" (On a new type of radiation). In the beginning of 1896 followed the second article: "Eine neue Art von Strahlen, II Mittheilung" (A new type of radiation - Communication II), and in 1897, another on "Weitere Beobachtungen über die Eigenschaften der X-Strahlen“" (Further observations on the properties of the X-rays). These short treatises contain the account of $\mathrm{X}$-rays discovery, and the well-known strange phenomenon. The discovery is of great importance from a purely scientific point of view, because it increased our knowledge. The knowledge so far completely eluded our eyes. It opened a new field of interest in science. The discovery is of great

\footnotetext{
${ }^{6}$ von Bezold W. to N.C., Jan. 27, 1901 (original in German).

${ }^{7}$ Fick A. to N.C., Jan. 18, 1901 (original in German).

${ }^{8}$ Koelliker R.A. to N.C., Jan. 14, 1901 (original in German).

9 von Pettenkofer M., Jan. 19, 1901 (original in German).

10 Zeuner G.A. to N.C., Jan. 14, 1901 (original in German).

11 Planck M. to N.C., undated letter (original in German).

12 Struve O. to N.C., Jan. 20, 1901 (original in German).

13 Dohrn A. to N.C., Jan. 23, 1901 (original in German).

14 von Hefner-Alteneck F. to N.C., Jan. 27, 1901 (original in German).

15 Reuleaux F. to N.C., Jan. 21, 1901 (original in German).

16 Warburg E. to N.C., Jan. 18, 1901 (original in German).

17 von Recklinghausen F. to N.C., Jan 27, 1901 (original in German).

${ }^{18}$ Hasselberg B., Arrhenius S., Hildebrandsson H., Thalén R., Angström S. to N.C., Undated Jan. 1901.
} 
importance from practical point of view. Due to these reasons, it could be said to be of "the greatest benefit for the mankind", and rewarding it with Nobel Prize will be in accordance with the Will of the founder. According to our view Roentgen's discovery is in itself of the great importance, that it is worth to be rewarded with the undivided Nobel Prize.

Yet, we allow us to suggest that the Nobel Prize in Physics this time be divided between Roentgen and Lenard. Latter's work will be described as follows - His pioneer investigations on the cathode rays are of great scientific merits. They fully compete with Roentgen's work. We find it quite difficult to decide for an unshared Prize, especially as their discoveries are intimately associated with each other. In the past the scientific equivalence of two researchers has been asserted by the scientific community, as is evident from the following facts - In 1896 the Academy of Sciences, Vienna, awarded the Baumgarten Prize to both. Two years later the Paris Academy honoured the two with the La Caze-Prize.

The Nobel Committee gave the background - How J.W. Hittorf's, W. Crookes' and H. Hertz's work was extended by Lenard, which led to the discovery of the cathode rays. On Jan. 12, 1893, at the Berlin Academy, Lenard gave the first report on: "Ueber Kathodenstrahlen in Gasen von atmosphärischem Druck und im äussersten Vacuum" (On the cathode radiation in gases at atmopheric pressure and high vacuum). It was published in "Wied. Ann." 51, 1894, under the same title. Then followed "Ueber die magnetische Ablenkung der Kathodenstrahlung" ("Wied. Ann." 52,1894 ) (On the deviation of cathode rays with magnetic field) and "Ueber die Absorption der Kathodenstrahlen" "Wied. Ann." 56, 1895 (On the absorption of cathode radiation). In these treatises, all of which preceded Roentgen's discovery, Lenard showed that cathode rays could be produced outside the discharge tube. He studied their characteristics. He observed their absorption and diffusion capacity by various bodies. He showed that the cathode rays can cause phosphorescence; influence photo-plates even if they are protected from the influence of visible light. Finally he showed that there are different types of cathode rays, which are affected differently by strong magnetic forces. He was the first person to produce a kind of spectrum of cathode rays.

The Nobel Committee was of the opinion that Lenard, no doubt was able to produce X-rays; although their distinctive from the cathode rays escaped his attention. Hence the merit goes to Prof. Roentgen for the discovery. It is clear, however, that Lenard was very close to the discovery of X-rays, and doubtless he can be counted as Roentgen's most important predecessor. Prof. Lenard has even later successfully continued his important studies over the cathode rays, as the following treatises show: (The N.C. produced a short list of publications).

On the bases of these facts, the motivation for the shared Prize is fully justified, wrote the members of the Nobel Committee.

\section{Decision of the Royal Swedish Academy of Sciences}

According to the Status of the Nobel Foundation, the Nobel Committee can only propose candidates. The final decision is taken by the Royal Swedish Academy of Science. As no record of the meetings of the Academy is kept, thus, it remains a secret - Why the academy decided for or opposed a particular candidate? In the past, sometime it happened that the candidates proposed by the Nobel Committee were completely ignored. For instance in 1908 the N.C. Proposed M. Planck; whereas the Academy decided for G. Lipmann. Similarly the Academy selected W. Wien, in contrast to A. Gullstrand, who was proposed by the Committee (Küppers et al. 1982, pp. 84-85). 
On the whole, the decision of the Academy is quite logical due to the following reasons: (a) The Nobel Committee itself said that Roentgen's discovery alone is worth of the Nobel Prize. (b) The argument of the Nobel Committee was not quite convincing, when it said that "their (X-rays) distinction from the cathode rays escaped his (Lenard's) attention. (c) Also the argument that "Lenard was close to discovery." (d) Their discoveries are intimately associated with each other. Even today, nobody will accept the last three arguments, if there is a question of priority over the discovery.

The decision of the Academy was fatal for Roentgen-Lenard relation. Lenard, who at the time of the X-rays discovery congratulated to the discoverer, and later had quite friendly relation with him (Peh, 1995, pp. 554-558); after the award of the Nobel Prize to Roentgen, saw his personal defeat. He became Roentgen's “enemy”. During Nazi Regime Lenard represented the "Deutsche Physik" (German physics) and wrote four volume. He ignored not only Jews contribution, such as Albert Einstein's theory of relativity, but also he did not mention with a single word about X-rays (Heilbron, 1996, pp. 60-66).

\section{Why Bringing P. Lenard in the Game?}

In the $20^{\text {th }}$ century many articles have been written on W.C. Roentgen and the X-ray discovery ${ }^{19}$ (Stanton, 1896, pp. 274-276; Watson, 1945, pp. 281-291; Müller, 1946, pp. 191-121; Peh, 1995, pp. 437-441; Hübner, 2000 a; Hübner, 2000 b) and the controversy between Lenard and Roentgen (Heilbron, 1996, pp. 60-66; Eisenberg, 1993, p. 62). However, they do not give the right picture of the affairs. Most of them are shadowed by "Nazi politics." Thus it is important to say a few words about the fact - How the scientific community saw
Lenard's and Roentgen's contribution shortly after the discovery of the X-rays?

The British scientific community was informed about Roentgen's discovery by A. Stanton. For "Nature" he translated W.C. Roentgen's German article under the title: "On a new kind of rays." In that he showed how Hertz's work lead to Lenard's discovery of the cathode rays. Roentgen's discovery followed after that (Stanton, 1896, pp. 274-276).

A.A.C. Swinton, who repeated Roentgen's experiments, as a continuation to the above article, wrote:

The newspaper reports of Prof. Roentgen's experiments having, during the past few days, excited considerable interest. The discovery does not appear, however, to be entirely novel, as it was noted by Hertz that metallic films are transparent to the cathode rays from a Crookes or Hittorf tube, and in Lenard's researches, published about two years ago, it is distinctly pointed out that such rays will produce photographic impressions. Indeed, Lenard, employing a tube with an aluminium window, through which the cathode rays passed out with comparative ease, obtained photographic shadow images of cardboard and aluminium interposed between the window and the photographic plate (emphasis added).

(Swinton, 1896, pp. 276-277).

Now, what about the discovery? Swinton added that Roentgen has extended results obtained by Lenard in a manner that has impressed the popular imagination, while, perhaps most important of all, he has discovered the exceedingly curious fact that bone is so much less transparent to these radiations that flesh and muscle, that if a living human hand be interposed between a Crookes tube and a photographic plate, a shadow photograph can be obtained which shows all the outlines and joints of the bones most distinctly. (Swinton, 1896, pp. 276-277).

\footnotetext{
${ }^{19}$ For the history of X-rays in Indian context, see, Roy S.C., Early years of X-rays research in India, Sci. Cult., 81 (2015): 72-75; Roy S.C., Discovery of X-rays and its impact in India, Indian J. Hist. Sci., (forthcoming).
} 
Evidently, after the discovery scientists outside Germany saw Roentgen's work based on Lenard's lines. This explains the attitude of the member of the Nobel Committee. However, these authors ignore the following fact - After the announcement of the X- rays discovery, in 1896, 49 Books and Brochures, and 1044 articles were written world-wide in the same year (Glasser, 1931, pp. 328-367).

P. Lenard was nominated again in 1902 , 1903, 1904 and 1905 with 1, 1, 3 and 2 proposals respectively (Crawford, 2002, pp. 22-31). He received the Nobel Prize in 1905 "for his work on cathode rays"

\section{W.C. Roentgen And the Nobel Lecture}

According to $\S 9$ “... It shall be incumbent on a prize-winner, wherever feasible, to give a lecture on the subject treated of in the work to which the prize has been awarded; such lecture to take place within six months of the Founder's Day at which the prize was won, and to be given at Stockholm...." (Crawford, 1987, p. 224)

Roentgen never delivered such a lecture (http://nobelprize.org..). Why not? Some historians argue that Roentgen "shunned the limelight. An indifferent speaker, he avoided giving the required Nobel Lecture; ... a shy man, he fled the festivities in Stockholm as quickly as he could; a modest man, he did not tout himself or relish the many prizes, medals, and decorations he received" (Heilbron, 1996, pp. 60-66).

The above arguments are not quite convincing, because, as we have seen above he received awards from Vienna and Paris Academies. In order to find out more, it will be worth to consult the documents of the Nobel Foundation (detail below).

Not later than December 10, 1901, that is, the day of the award ceremony of the Nobel Prize, Roentgen was informed that he needs to deliver lecture.

On April 7, 1902, he wrote to S. Arrhenius that he had already written a letter from Italy, which he did not get. In the letter he had proposed whether during Easter week (20-25 May) or end of July or beginning of August, will be suitable for the Nobel lecture ${ }^{20}$. However, he will prefer the second date as in Bavaria there are no Easter vacation as throughout Germany. In that case he had to take leave and miss the lectures, which he will not do with pleasure. ${ }^{21}$

According to the Minutes of the Royal Swedish Academy of Sciences Stockholm (R.S.A.S.), Arrhenius suggested Roentgen that summer period will not be a good time as most of the members of the academy would not be there to attend the lecture. After that Roentgen sent a letter and told he will come to Stockholm in September or the beginning of October in 1902.22 According to the translated summary of Roentgen's letter (original is German) of Oct. 10, 1902:
There was a sudden change, as yesterday noon the information (due to Hasselberg's letter) crossed my plans. Without getting reply from Sweden, I had planned the visit. I and my wife were ready for the visit. Professor Hasselberg wrote that according to the status of the Nobel Foundation, the lecture is wished but it is not necessary. Under these circumstances, I am very much inclined not to travel. Still I will like to know, whether the Nobel Committee will be annoyed if I stay away ${ }^{23}$.
Further: "I hope and believe that you will mind it. From our correspondence you know well, how earnestly I have been to my duties - I

\footnotetext{
${ }^{20}$ Roentgen W.C. to Arrhenius S., April 7, 1902 (original in German).

${ }^{21}$ Roentgen W.C. to Arrhenius S., Ibid.

${ }^{22}$ Private communication, Maria Aps, archivist Royal Swedish Academy of Sciences to R. Singh, June 12, 2009.

${ }^{23}$ Roentgen W.C. to Arrhenius S., Oct. 10, 1902 (original in German).
} 
followed the Paragraphs of the Nobel Status, till I was taught differently by Hasselberg". ${ }^{24}$

Why he did not deliver lecture after the Nobel Prize ceremony? Roentgen said in his letter that the authorities of his universities were not very cooperative $^{25}$. What was the real problem? It is not mentioned in the letter. Almost apologetically he wrote: "I am mentioning this, so that the Gentlemen from the N.C. and particularly you, who were friendly to me, have no reasons to be unsatisfied $^{26}$.

Obviously, Hasselberg was responsible for giving advice not to deliver lecture. It is unknown, whether he was informed about Arrhenius-Roentgen correspondence. The fact is that according to the Minutes of the R.S.A.S. of Nov. 5, 1902, Arrhenius draw attention to the fact that Roentgen still hasn't held the lecture. He asked the permanent secretary of the R.S.A.S. to write to Roentgen in a kind, but firm way to deliver lecture at a time of his convenience. The Academy discussed the matter and decided that there was no reason to follow Arrhenius' suggestion. However, they give the right and the task to the permanent Secretary - In future to inform the new laureates about the winning of the Nobel Prize, and the utmost importance of delivering the Nobel lecture as soon as possible, and preferably at the time of Nobel Prize ceremony ${ }^{27}$.

To end with this section, it should be mentioned that Roentgen was not a special case to ignore the lecture. In the case of the Nobel Peace Prize the first two laureates, Henry Dunant and Frédéric Passy, neither attended the ceremony, nor delivered the lecture (Boeschenstein et al. 1987, p. 190).

\section{The After Myth of the Nobel Prize}

It is very likely that after getting the Nobel Prize, Roentgen had tussle not only with P. Lenard but with other German physicists. This made him a bitter man. It can be supported with the following statement:

\begin{abstract}
"The challenge to his title of discoverer, which began early in 1896, soured him on X-rays and honors. Rontgen allowed these attacks to embitter him, although his right to the discovery was certified by the Nobel Prize and upheld by all knowledgeable colleagues apart from Lenard's clique. So aggrieved did he become that he ordered that all his papers concerning X-rays during the period 1895-1900 be burnt unopened after his death" (Heilbron, 1996, pp. 60-66).
\end{abstract}

After receiving the Nobel Prize, Roentgen had the permanent right of nomination for the Nobel Prize. In the following we shall see "his" candidates.

\section{Roentgen as Nominator}

Roentgen's first nomination was in favour of Lord Kelvin, Edinburgh, for his work published in "Philosophical Magazine" and other journals. It was a nomination for nomination sake, as he was unable to find a candidate with an important discovery from the preceding year ${ }^{28}$. Two years later, again, he nominated Lord Kelvin. He argued that Kelvin contributed to theoretical and experimental physics. His scientific researches are far better than any other living scientist. It will be wrong, if this highly recognised elderly scholar had to die without having received the high honour - the Nobel Prize ${ }^{29}$. In 1905, in a joint letter with H.A. Lorentz, Roentgen nominated L. Kelvin. In a short letter they argued that they are persuaded - if

\footnotetext{
${ }^{24}$ Roentgen W.C. to Arrhenius S., Ibid.

25 Roentgen W.C. to Arrhenius S., Ibid.

26 Roentgen W.C. to Arrhenius S., Ibid.

27 Private communication, Maria Aps, archivist Royal Swedish Academy of Sciences to R. Singh, June 12, 2009.

28 Roentgen W.C. to N.C., Jan. 27, 1901 (original in German).
} 
the Nobel Prize is awarded to the learnt scholar all physicists would have the deepest satisfaction ${ }^{30}$. Five years later in a very short letter Roentgen proposed the Swede, K. Angstrom, Uppsala, "for his excellent works in the field of radiation. ${ }^{31}$ "

In 1917, Roentgen proposed Max Planck, Berlin, for "his basic works on quantum theory" Also four other scientists proposed Planck. Roentgen, in his last nomination in 1922, proposed Albert Einstein and Niels Bohr. He observed that Einstein's works on Brownian movement, photochemical reaction and magnetism were important for experimental researches. So far as the theory of relativity was concerned, Roentgen was rather careful. Like most the experimental physicist, for him a theory can be seen as correct, only if it is verified experimentally. He was afraid that if the Prize is given for it and later it proves to be wrong, it may bring the Nobel Committee in a precarious situation $^{\frac{33}{}}$.

Roentgen with full conviction and great joy proposed N. Bohr for his investigations on the Rutherford-Bohr atomic model, which has produced beautiful and important results in the fields of spectral analysis and atomic structure ${ }^{34}$. In 1922 N. Bohr, who was nominated by 11 scientists (including Roentgen) (Crawford, 2002, pp. 84-85).

For the year 1921 the Nobel Committee saw none of the nominees as worth of the Nobel Prize. It was reserved and awarded to A. Einstein in 1922(http://www.nobelprize.org..). N. Bohr was awarded with the Physics Nobel Prize in 1922 "for his services in the investigation of the structure of atoms and of the radiation emanating from them" ( http://www.nobelprize.org..).

\section{Concluding Remarks}

From the forgoging we see that:

- The beginning of the Physics Nobel Prize was quite difficult. Not only the Nobel Committee, but also the nominees and nominators had problem in interpreting the status of the Nobel Foundation. Such problems are typical for a new founded institution.

- The members of the Nobel Committee tried to push the case of P. Lenard for the Nobel Prize, by nominating and even writing detailed report in his favour. By neglecting this claim, the Royal Swedish Academy of Sciences, Stockholm, demonstrated its power. It was established in the future. For instance, the Academy awarded Prizes to G. Lipmann and W. Wien, instead of the persons proposed by the N.C. (Küppers et al. 1982, pp. 84-85).

- W.C. Roentgen's discovery had some sort of "show-effect", which fascinated not only the scientific community, but also the general public. Apart from that its technique was "simple." Not surprisingly, a great number of articles and books were published within a very short period of one year. It is very likely that the members of the Royal Swedish Academy of Sciences, Stockholm were impressed by these facts and gave their decision in Roentgen's favour. In contrast, Lenard's cathode rays had no appeal for non-experts.

- Due to lack of good communication among the laureate, members of the Nobel Committee and the Secretary of the Academy and difficulty created by the management authorities of

\footnotetext{
${ }^{29}$ Roentgen W.C. to N.C., Jan. 24, 1903 (original in German).

${ }^{30}$ Lorentz H.A., Roentgen W.C., (undated) Jan. 1905 (original in French).

${ }^{31}$ Roentgen W.C. to N.C., Jan. 30, 1910 (original in German).

${ }^{32}$ Roentgen W.C. to N.C., Jan. 15, 1917 (original in German).

${ }^{33}$ Roentgen W.C. to N.C., Jan 23, 1922 (original in German).

${ }^{34}$ Roentgen W.C. to N.C., Ibid.
} 
the University of Munich, Roentgen did not deliver the lecture. Evidently the opinion given by the historians in the past on this issue are not correct.

- The authorities of the Munich University were not ready to give Roentgen "free days" to deliver lecture. This indicates that the Nobel Prize in the beginning was not seen as prestigious as we know today.

To close with, it should be mentioned that with the time Nobel foundation learnt the lesson to interpret founder's Will differently. In future the Prizes were awarded not only for the discovery/invention during the preceding year, but even after long time - After the importance of the discovery became clear. For example Max Born was awarded the Nobel Prize in 1954 for his work on the interpretation of wave function from the year 1926 (Singh, 2013, pp. 79-104). The extreme example is that of the Dene Jens Christian Skou, who received the Chemistry Nobel Prize in 1997, "for the first discovery of an ion-transporting enzyme, $\mathrm{Na}+$, K+ -ATPase." His discovery predated the Prize by forty years.

\section{ACKNowledgements}

Thanks are due to the Editor of the "Indian Journal of History of Science" for the editorial work. The nomination letters, experts' reports as well as the reports of the Nobel Committee regarding the Physics Nobel Prizes were sent to me by Mrs. Maria Asp Dahlbaeck - Archivist, the Royal Swedish Academy of Sciences, Stockholm. I am grateful to her for helping me during the last 15 years. I am thankful to Prof. Dr. Michael Komorek, Head of the Research Group - Physics Didactics and History of Science, University of Oldenburg, for supporting my research work by providing research facilities.

\section{BibliograPhy}

Boeschenstein, H.; Brassel-Moser R.; van Harten M., et al. Beginn einer Geschichte - Friedens-Nobelpreis 19011904, Pacis AG Zug, ,Luzern, 1987, p. 190; http://www. nobelprize.org/nobel_prizes/peace/laureates/1901/ address.html, May 8, 2016.

Crawford, E.; Heilbron, and The Nobel population 19011937 , p. 224.

Crawford, E.; Heilbron, J.L.; Ullrich, R. The Nobel Population 1901-1937, Office for History of Science, Uppsala, California, 1987, pp. 20-21.

Crawford, E. The beginnings of the Nobel Institution - The science Prizes 1901-1915, Cambridge University press, Cambridge, 1987, p. 224.

Crawford, E. The Nobel population 1901-1950, Universal Academy Press, Inc., Tokyo, 2002, pp. 20-21.

Eisenberg, R.L. Cathode rays and controversy, AJR, 160 (1993): 62.

Glasser, O. Wilhelm Röntgen und die Geschichte der Röntgenstrahlen, (in: Röntgenkunde in Einzeldarstellungen, Band 3, Berg H.H., Frik K. (Eds.)), Springer Verlag, Berlin, 1931, pp. 328-367.

Heilbron, J.L. X-rays in the history of science, Physica Scripta, 61 (1996): 60-66.

http://nobelprize.org/nobel_prizes/physics/laureates/1901/ rontgen-lecture.html

http://www.nobelprize.org/alfred_nobel/will/index.html/ will-full.html. May 9, 2016.

http://www.nobelprize.org/nobel_prizes/physics/ laureates/1921/, May 8, 2016.

Hübner, K. Die zwei ersten Zeitungsberichte über Röntgens Entdeckung, ERS Verlag, Berlin, 2000a.

Hübner, K. Eugen Goldstein und die frühe Verwertung der Roentgenschen Entdeckung in Berlin, ERS Verlag, Berlin, 2000b.

Küppers, G.; Weingart, P.; Ulitzka, N. Die Nobelpreise in Physik und Chemie 1901-1929, B.K. Blitz-Druck GmbH, Bielefeld, 1982, p. 19.

Müller, A. The background of Roentgen's discovery, Nature, 157 (1946): 191-121.

Nielsen H., Nielsen K. (Eds.), Neighbouring Nobel - The history of thirteen Danish Nobel Prizes, Aarhus University Press, Aarhus, 2001, 
Peh, W.C.G., Roentgen and his discovery of the X-rays - Part I, Singapore Med. J., 36 (1995): 437-441;

Peh, W.C.G., Controversy surrounding and following discovery - Part II, Singapore Med. J., 36 (1995): 554-558.

Report of the Nobel Committee, 1901 (original in Swedish).
Singh, R., Belated Nobel Prize for Max Born FRS, Ind. J. Hist. Sci., 48 (2013): 79-104.

Stanton, A., On a New Kind of Rays, Nature, 53 (1896): 274-276.

Swinton, A.A.C., Professor Roentgen's discovery, Nature, 53 (1896): 276-277.

Watson, E.C., The discovery of the X-rays, American Journal of Physics, 13 (1945): 281-291. 